\title{
Pharmacy: A Dignified Profession but yet Deserted; A Dilemma for Pharmacy Profession and Future Pharmacist
}

\author{
Abbas $S^{1,2}$, Qamar $F^{1}$ and Naveed $\mathbf{S}^{1 *}$ \\ 1 Jinnah University for Women, Pakistan \\ ${ }^{2}$ University of Karachi, Pakistan
}

\begin{abstract}
Pharmacy is the most renowned and respectable profession in the world as the association of this profession with Allied Healthcare. The foremost reason to portray this entire fact is to highlight the problems and struggle face by our young fresh pharmacist and also to help out our junior undergraduate pharmacists in order to prevent them from problematic career disasters. Pharmacist Professionals from each respective fields needs to do preventable majors to prevent our future pharmacist from the troublesome issues that are prevailing in our main society, consequently at this moment there is a chief and upmost accountability of a Pharmacist community to ensure the stable future of young undergraduate future pharmacist and ascend their significance because they deserve recognition and respect for their services and revolutionize this entire wretched and miserable situation of the pharmacy profession in Pakistan.
\end{abstract}

Keywords: Pharmacy; Allied healthcare; Pharmacist; Undergraduate future pharmacist

\section{Letter to Editor}

Choosing a career in the field of pharmacy profession, appear to be a challenging journey as in Pakistan we have been heard that there is much scope of pharmacy but later we came to realize that it's not just a bed of roses but a bed of thorn somewhat because the value, worth and availability of pharmacist in our society is just nominal and apparent. Nobody recognize this profession and the main catch-22 is no surety of getting a job after passing your whole Phar.D. with flying colors.

In Karachi, Pakistan there are total 9 institutions offering the course of Phar.D. So in this way there are thousands of students pass out annually including those institutions which are coupled with Morning and evening Shifts, as quantity of students become twice and the scenario of city is like there are less sources of job in every field of pharmacy, if we talk about some particular fields like as Industrial pharmacy there are less number of National Pharmaceutical industries with few Multinational, In Hospital and clinical pharmacy unfortunately pharmacist are not welcome anymore with true dignity. In most of the Health care centers if they do exist they mostly get the exposure of hospital pharmacy and very few accommodate clinical pharmacist and merely a small number of hospital settings do have well established pharmacy. Now coming towards another field i.e. Community Pharmacy which are running by local laymen without any knowledge and skill of pharmacy and not even they have a proper and well established temperature controlled pharmacy with no counseling of the patients.

Talking about a supplementary field i.e. the research and development, mostly a fresh graduate is unaware of this situate since they don't get any chance or opportunity to work with researchers and scholars. Hardly some fortunate students may get a chance to work and galvanized their research skills during their undergraduate level.

\section{Now the fact}

Many students after passing out go down in a deep state of depression, stress and anxiety due to face these hurdles of not getting a desired job or less paid jobs because a fresh graduate wants to start their career as soon as possible nevertheless many obstacles came across in their approach as major discussed above. Now there is a high time to be acquainted with this state and acknowledge that we are belonging to such a worth taking profession and have to change this entire scenario because this can only be done by a pharmacist as they will raise their voice for the betterment of our future pharmacist by providing them a proper platform, indulge the students with small group projects in distinct fields so our students become aware and sound technical, provide them a practical approach. We are the most admirable persons among the globe, don't compromise less than what you deserve, make yourself competent to tackle this situation and work for the betterment of this Profession as nobody going to take us out from this trash except a pharmacist by itself since if we invest in our future pharmacist they will certainly construct our future bright.

The foremost key to success are communication with distinct fields, proper career counseling and CME (continuing medical education) for our undergraduate apprentice to cope up this hard tussle and make them competent enough to face challenges.

Furthermore, by the help of creating awareness among the citizens of the society and embark our existence as a core health care professionals. Hence we would be able to enlighten this noble profession.

\section{Author Contribution}

Syeda Sarah Abbas and Fatima Qamar discussed these facts in a form of report in Dr. Safila's supervision. This article is based upon the current situation of fresh pharmacist and there is a high need of demand to raise this question for the betterment of our future pharmacists and pharmacy professionals.

*Corresponding author: Naveed S, Faculty of Pharmacy, Jinnah University for Women, Karachi, Pakistan, Tel: 00923002621917; E-mail: safila117@yahoo.com

Received April 01, 2015; Accepted April 22, 2015; Published April 29, 2015

Citation: Abbas SS, Qamar F, Naveed S (2015) Pharmacy: A Dignified Profession but yet Deserted; A Dilemma for Pharmacy Profession and Future Pharmacist. J Bioequiv Availab 7: e65. doi:10.4172/jbb.10000e65

Copyright: $\odot 2015$ Abbas SS, et al. This is an open-access article distributed under the terms of the Creative Commons Attribution License, which permits unrestricted use, distribution, and reproduction in any medium, provided the original author and source are credited. 


\section{Author Information}

Syeda Sarah Abbas is a Lecturer \& Academic Researcher at Faculty of Pharmacy, Jinnah University for Women. She has covered the departments of production and quality assurance in her early career days in different pharmaceutical industries of national repute. Moreover she is also enrolled in Masters in Philosophy Program at Faculty of Pharmacy, University of Karachi in Department of Pharmaceutics.
Fatima Qamar is a Lecturer \& Researcher at Faculty of Pharmacy, Jinnah University for Women and doing Post graduation i.e. M.Phil. in Pharmaceutical Chemistry from Jinnah University for Women. Dr. Safila Naveed is an Associate Professor at Faculty of Pharmacy, Jinnah University for Women. She has authored and co-authored many research articles and publications nationally and internationally and as well as she is the in charge of M.Phil. Program at Jinnah University for Women. 